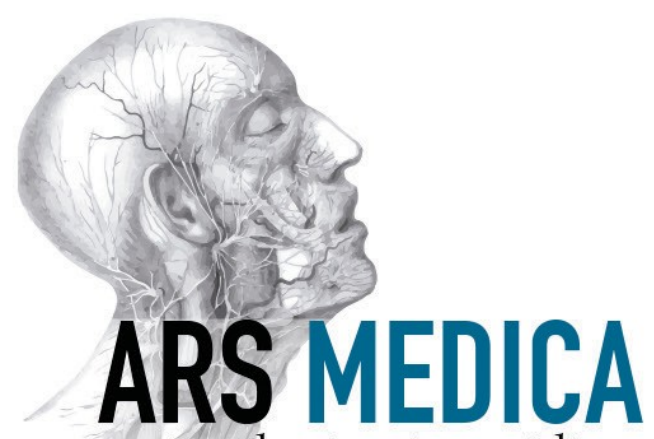

El presente artículo corresponde a un archivo originalmente publicado en Ars Medica, revista de estudios médicos humanísticos, actualmente incluido en el historial de Ars Medica Revista de ciencias médicas. El contenido del presente artículo, no necesariamente representa la actual línea editorial. Para mayor información visitar el siguiente vínculo: http://www.arsmedica.cl/index.php/MED/about/submissions\#authorGuidelines 


\title{
La dignidad del embrión humano. ¿Qué sentido tiene que se le niegue al embrión humano el derecho a vivir?
}

\author{
Dr. Juan de Dios Vial Correa \\ Profesor Titular Facultad de Medicina \\ Pontificia Universidad Católica de Chile \\ Dr. P. Ángel Rodríguez Guerro \\ Profesor Asociado Adjunto \\ Facultad de Medicina \\ Pontificia Universidad Católica de Chile
}

\section{Resumen}

El concepto de "dignidad humana” ha ido evolucionando en la historia de la culturaoccidental hasta verla como algo intrínseco a la persona humana y no vinculado a una o más de las cualidades del ser humano con más o menos gradación; "todas las cosas tienen precio; pero el hombre tiene dignidad”. Más bien, es propio cuando el hombre pierde sus cualidades físicas, intelectuales, morales que resplandece más su pura dignidad. Por tanto, si el embrión es un ser humano (porque ha empezado un desarrollo específicamente humano) se le debe el mismo respeto que a un adulto. Negarle este respeto, como ocurre con frecuencia, significa haber elegido una ética racionalista, utilitarista, de búsqueda de consensos sociales, una ética que ha reducido el ser humano a objeto. Sólo una concepción del ser humano como ser abierto al Absoluto, un “yo inhabitado por Dios” (F. Rielo) tendrá la garantía de ser respetado en su dignidad, siempre y por todos.

palabras clave: embrión; persona; dignidad; ser humano; bioética.

\section{THE DIGNITY OF THE HUMAN EMBRYO WHAT IS THE SIGNIFICANCE OF DENYING HUMAN EMBRYOS}

\section{THE RIGHT TO LIVE?}

The concept of human dignity has developed in western culture until it is now seen as something intrinsic to human beings and not linked to one or more of the qualities of human beings to a greater or lesser degree. "All things have a price; but man has dignity". In fact, it is precisely when man loses his physical, intellectual and moral qualities that his dignity shines most. Consequently, if the embryo is a human 
being (because a specific human development has begun), he/she deserves the same respect as an adult. To deny this respect, which is often the case, means choosing rationalistic or utilitarian ethics, in search of social consensus, an ethicthat reduces human beings to things. The article ends with an analysis of changes in the concept of dignity after 1948 according to the Human Right Universal Declaration of Human Rights. The individualistic conception transformed the way to understand dignity. Only a conception of human being as a being open to the Absolute, an "I inhabited by God" (F. Rielo), will guarantee to respect him in his dignity, always.

Key words: dignity; bioethics; person; human being; embryo.

\section{Introducción}

La causa de la defensa de la vida nos convoca de muchas maneras. Es un hecho curioso que en este siglo, dotado de tantas posibilidades y adelantos para mejorar ypromover la vida, se haya hecho tan urgente la simple tarea de defenderla. Sentimosque la vida se halla amenazada, y lo vemos de mil maneras en las múltiples formas,muy poco respetuosas, en que están siendo tratados los embriones humanos en muchas partes del mundo. No es casualidad. En el mundo contemporáneo late una actitud de desprecio y pesimismo frente a la vida, y nosotros nos sentimos llamadosa reivindicarla, a exaltarla, y a defenderla. Esa ${ }^{1}$ tarea de defensa tiene múltiples aspectos. Algunos de ellos son los que representan los movimientos Pro-Vida, perotiene que desarrollarse en la misma línea y bajo modalidades diversas una actividadincesante, sostenida en su intensidad y en su fervor, en la defensa del mismo ideal con medios diversos.

Tomemos el caso de la fertilización in vitro. Lo que generalmente preocupa a los medios científicos y médicos es el grado de eficacia que el procedimiento alcance,así como la seguridad psicológica de la madre y el impacto sobre la convivencia civil. La Iglesia Católica se pregunta sobre el significado del procedimiento, sobre su sentido. Porque el acto conyugal que engendra un hijo es fundamentalmente un acto de relación entre personas, entre un hombre y una mujer. El procedimiento quefecunda un huevo en el laboratorio es una cadena de pasos tecnológicos. Un poco de reflexión muestra que se trata de dos formas enteramente distintas de encarar el problema de la procreación.

Sabemos que cada uno de los pasos de la técnica puede ser moralmente objetado, pero se pretende justificar esas transgresiones en nombre del fin perseguido. No se trata sólo de que el fin no justifica 
los medios. Se trata también de queesos medios no lícitos están encadenados en un procedimiento técnico, y pueden entonces ser sustituidos por otros que sean más eficientes: si no son buenos los espermatozoides de los que se dispone ¿por qué no se podría usar otros, de un "dador" distinto? Si los óvulos no son buenos, se tratará de buscar los mejores; si el vientre no es adecuado, no hay por qué no hallar un sustituto, un vientre de alquiler o de préstamo; si son demasiados los embriones, se los puede seleccionar y desechar los que no "sirven". Habrá por supuesto que encontrar algún sistema legal que resguarde a la sociedad de algunos excesos peligrosos para la convivenciasocial: por ejemplo, ¿̇erá inconveniente que se use el semen de un solo individuo en muchos ensayos con mujeres diferentes? Porque se arriesga producir parientes consanguíneos ignorados en número indeseable. Lo que ocurre es que en vez de procrear un hombre se está produciendo industrialmente un ser humano; y la ley dela producción es la eficiencia. Lo que vemos aquí es que, en su punto más sensible, que es el de la generación de una nueva vida, el ser humano se ha hecho objeto de la técnica, ha dejado de ser mirado como persona. No es el momento de entrar en esto en profundidad sino sólo de señalar que detrás de la técnica médica hay aquí una nueva mirada sobre el hombre, que se transforma en objeto de manipulación técnica sin otras reservas que las del consenso o la conveniencia social. La ciencia ha mostrado que no es neutra frente a la realidad humana, por el contrario: si no mira al hombre entero, lo desintegra. Si mira al hombre entero, todos los adelantos de la ciencia son benéficos, son positivos, son enriquecedores de la vida. Si mira a un hombre fragmentado, todos los adelantos son peligrosos, son ambiguos.

Como otro ejemplo, recordemos el empleo sistemático y masivo de los métodosquímicos, hormonales, para regular la natalidad. Esto no es un mero asunto de eficacia técnica sino que supone una manera distinta de mirar la unión conyugal y, por lo tanto, una manera distinta de mirar al ser humano. De nuevo lo mismo, que en estecaso fue denunciado de modo elocuente por Pablo VI en la Humanae Vitae ${ }^{2}$.

La disociación tecnológica del aspecto unitivo y el aspecto procreativo en la relación entre el varón y la mujer significa introducir un concepto nuevo desexualidad y, por lo tanto, de humanidad, y obliga a inventar una serie de criterios de valoración para las relaciones de los sexos que partan de la base de que el sexo, esa fuerza primordial de la naturaleza humana, ha perdido su sentido básico y se ha disociado del ejercicio integral de la vida personal. Se produce necesariamente unarevolución de las relaciones sexuales. Lo que se llama una liberación sexual, o el sexo seguro, no es más que el desprenderse del sexo de la integridad de la persona, de su responsabilidad, su inteligencia y su voluntad, y la 
provocación consiguiente de la desintegración en la noción misma de la persona.

En cada uno de estos casos la voz de la civilización tecnológica nos habla de adelantos; la voz de la humanidad nos habla de distorsiones, de mutilaciones. Yeste contraste se debe justamente a que hay una diferencia entre mirar al hombre como un objeto de cualquier posible modificación técnica que a él le parezca útil

o deseable, y mirarlo como una criatura racional y libre que debería ser el señor de la técnica. El buen sentido dice que esta modificación de la mirada sobre el hombre entraña el más explosivo ingrediente en la vida social. Al cambiar así la noción de hombre tiene que cambiar la sociedad, tienen que cambiar radicalmente las formas de convivencia social, y no podrán hacerlo sino en el sentido de hacer al hombre cada vez más esclavo de sus técnicas, cada vez en mayor medida un objeto elaborado por sus propias tecnologías. Esta tecnificación de lo reproductivo y lo sexual es la antesala de la esclavización del hombre.

Estos dos problemas que hemos mencionado, el de la fertilización artificial yel de la sustitución del control voluntario de la vida sexual por un control químicou hormonal, son problemas de los últimos treinta años. El momento histórico tiene sin embargo otra dimensión, que es la del futuro. Hay grandes problemasnuevos que están surgiendo en el horizonte. El problema de la manipulación genética ya es una realidad incipiente. El conocimiento del genoma humano es yauna realidad en este siglo XXI. La marcha del progreso científico y tecnológico es acelerada, vertiginosa a ratos. El buen sentido y la pasada experiencia nos dicen que todos esos adelantos pueden ser positivos si se los aborda con una ideaintegral del hombre; pueden ser destructivos $-\mathrm{y}$ hasta un punto que no podemosni siquiera imaginar- si se los aborda con una idea mutilada del hombre. Y por lo mismo, el solo anuncio de esos adelantos exige una reflexión metódica sobreellos, sobre sus implicaciones para el destino humano. En suma, un gran trabajointelectual anticipativo.

\section{La persona humana: más que todo método y más que toda ciencia}

La palabra "misterio" es central en el cristianismo. Hablamos del Misterio de la Trinidad, del Misterio de la Encarnación, del Misterio de la Cruz. Pero al hablar así no lo hacemos sólo porque se trata de realidades que sobrepasan nuestra razón sino por algo mucho más profundo. Al fin y al cabo, hay muchas cosas que no entendemos, 
cosas que guardan sus secretos y no las llamamos misterios en el mismo sentido de los que hemos mencionado.

En esos misterios de la fe el hombre toca-por así decirlo- el mismo ser de Diosque se revela. Un misterio es una manera en que la fuerza de lo divino se le manifiestaal hombre -no ciertamente a su análisis racional sino requiriendo, exigiendo a latotalidad del hombre, reclamando su amorosa aceptación y su fidelidad.

Hablar entonces del "misterio de la vida" equivale a decir que la vida es“sagrada”, que ella tiene la realidad, la consistencia de las cosas en las que Dios se revela. Este carácter sagrado de la vida humana ha sido puesto de relieve innumerables veces por Su Santidad Juan Pablo $\mathrm{II}^{3}$. Lo que estamos diciendo es que la vida es sagrada, porque en ella se manifiesta, se revela, Dios mismo.

Pero ¿cuál es esa vida que es sagrada, que es modo de manifestarse delmisterio de Dios, y que por esa manifestación se hace como fundamento de una nueva realidad?

A esa pregunta contestamos resueltamente que estamos hablando de la vida humana.

Esta es una afirmación que en nuestro tiempo tropieza con fuertes resistencias,de parte de quienes quisieran que la vida humana fuera poco más que un dato biológico, o sociológico o psicológico, para ser manejado por la técnica y la ciencia. Muy de moda está ahora en Chile, en los ambientes médicos laicos, la definición del ser humano como un ser "bio-psico-social".

Pero cada uno de nosotros al mirar hacia sí mismo sabe con certeza algunas cosas:

Todo ser humano aspira a la plenitud de la felicidad. Ya sea que se encuentre en la cumbre de la vitalidad y la alegría, ya sea que se halle sumido en el tedio o en el dolor, no puede vivir sin desear algo más, sin aspirar a ser más feliz. Nuestro corazónestá siempre inquieto, incierto y dividido, porque en cada recodo del camino presienteuna plenitud que no tiene, experimenta un deseo de absoluto que lo lleva a buscarla relación con otros que tienen también un valor absoluto, y que lo lleva a buscaraun sin quererlo, a un Absoluto que está más allá de los demás hombres y mujeres, y en el que intuye que podría saciar su sed de ser feliz: Fecisti nos ad Te Domine, et inquietum est cor nostrum donec requiescat in Te... decía San Agustín. 
En ese deseo de felicidad reconozco lo absoluto de mi condición humana: porque nadie quiere ser feliz para algo; cada cual quiere simplemente ser feliz, ser más feliz que ahora, y cada vez, en cada nueva circunstancia, se repite a sí mismo que quiere aquella felicidad que ahora no tiene.

Pero hay además algo que la más simple experiencia nos enseña. Todas lascosas que conocemos están en relación entre sí, pero el espíritu humano -únicoentre todas ellas- es en cierta forma todas las cosas, justamente por esa facultad deconocer, de conocerlo todo, por la que en el espíritu humano se recapitula, se reflejatoda la grandeza de la obra de Dios. Hay un aspecto en el que percibimos que el almahumana es más grande, que todo el universo, porque es capaz de escudriñarlo todo,porque la mente humana es capaz de convocar, por una especie de acto soberano, a toda la realidad para conocerla y juzgarla. Iluminado por esa misma luz, el hombre es capaz de amar, de actuar y de hacer, es capaz de encontrar la verdad y de adherir a ella por la libertad.

Si es verdad que cada uno de los hombres y mujeres es un valor absoluto, entonces no tiene nada de raro que la suprema realización del ser humano sea precisamente la relación con el otro, con su prójimo, que es también en cierta forma un absoluto, y que esa relación de encuentro sea el elemento decisivo de la vida humana. Y sabemos que esa relación de encuentro no puede ser auténticamente verdadera sino en la medida en que ella me abra a la relación definitiva y fundamental con el Otro, con mayúscula. El absoluto de la persona humana es como el signo del absoluto de Dios.

Esto significa que la vida humana está dotada de una especial dignidad, y estolo sabemos del modo más natural y espontáneo. Esa dignidad no se inclina, no le cede, a ninguna de las obras del hombre. ¿Qué pensaríamos de una ciencia excelente,que pareciera perfecta, pero que destruyera al hombre? Nos parecería detestable porque entendemos espontáneamente que el hombre es más, infinitamente más quetodos los productos de su espíritu, que todas las ciencias que ha creado, que todos los objetos que entiende e imagina. Sería una actitud reduccionista la de someter la dignidad del hombre y hacer de éste un simple objeto de la Biología, o de la Psicología o de la Sociología, o de cualquiera otra creación humana. El hombre es el autor de ellas, y en el núcleo mismo, habría una contradicción en someter al autor al dominio, al juicio de sus propias creaturas.

Pero -y eso es obvio, pero siempre olvidado- esta realidad de la persona se da enun cuerpo, sometido a todas las leyes que investigan las ciencias. Es mucha la gente que quisiera mirar al cuerpo como un 
instrumento, como una especie de máquina conla cual yo puedo hacer lo que quiero, porque lo que haga con él no me compromete a mí, no compromete el núcleo mismo de mi persona. Y eso es un trágico error: somosen un cuerpo, y todo lo que hagamos en él nos compromete enteros.

Esas afirmaciones que se desprenden de una consideración puramente racionalde la dignidad humana reciben una confirmación, y una nueva luz por la Revelaciónde Jesucristo.

Eso es lo que recalca el Concilio Vaticano II al hablar de "el hombre, única criatura terrestre a la que Dios ha amado por sí misma”, con palabras que ponen a lo humano en un sitio absolutamente especial. O la afirmación que el mismo Cristohace en San Juan, "dioses sois”"

En la fe conocemos cuál es la verdadera raíz de esta misteriosa grandeza del ser humano. Con palabras del Concilio, "sólo en el misterio del Verbo Encarnado se empieza a aclarar el misterio del hombre" ${ }^{5}$. La realidad misteriosa del hombre recibe su luz de que en ella se manifiesta en forma perfecta, en que es como el lugar escogido para la más admirable de las obras de Dios, la más adorable de sus manifestaciones que es la Encarnación del Verbo de Dios.

Así, lo que la inteligencia podía saber sobre el hombre se ve afirmado y sobrepasado más allá de toda medida imaginable por la acción de Dios que se revela a Sí mismo.

La fe nos muestra que la vida humana es más que digna, es sagrada porque es en ella donde ha escogido revelarse el misterio de Dios. La Revelación deJesucristo nos dice que no nos hemos engañado al pensar bien, al pensar altamente el hombre.

Basta con mirar en torno a nosotros para darnos cuenta de que esa es una verdadque es urgente proclamar, porque este siglo que vivimos, tan rico en maravillosos progresos, tan fuerte para abrir nuevas perspectivas, para aliviar sufrimientos, para procurar placeres, es sin embargo un siglo que ha pensado y que piensa bajamente del hombre. Cuántas veces se lo mira como a una creatura sin trascendencia y sin sentido; un individuo para ser movido por la propaganda, para que sean halagados sus sentidos, para ser explotado o burlado, un mero instrumento del poder, y no sólo del poder brutal de la fuerza sino de ese otro poder sutil que infiltra la sociedadinspirando valores antihumanos. Cuántas veces se piensa en el cuerpo como en una simple máquina, de tal forma que basta con que mis intenciones sean buenas para que el uso que le dé sea legítimo. 
Cuando decimos que la vida humana es sagrada, y que queremos partir de allí, estamos afirmando que en todas nuestras consideraciones médicas, biológicas,psicológicas que se refieran al hombre tenemos que partir del carácter absolutamenteúnico, irreductiblemente único del ser humano, que en su condición espiritual y corporal está abierto a la relación con Dios y con los otros. La persona humana es como la cumbre desde la cual miramos todos los aspectos biológicos, médicos, psicológicos del hombre, y sabemos que esa perspectiva enriquece nuestra mirada sobre cada uno de esos aspectos. La perspectiva, la mirada, no cambia por cierto un hecho biológico: éste sigue siendo el mismo; pero lo presenta bajo un ángulo distinto, con un significación diferente, revela cuál es su modo de inserción en la realidad global y nos permite determinar las condiciones bajo las cuales es lícito y positivo utilizarlo.

\section{Dignidad del embrión humano}

\section{1. ¿Qué es un embrión humano?}

La respuesta a la pregunta ¿qué es un embrión humano? es casi engañosamentesimple. Es un organismo de la especie humana ${ }^{6}$. Pero para entender esta respuesta en sus implicaciones hay que clarificar los términos.

Un organismo es una unidad discreta, una entidad biológica que se distingue claramente de su medio, del cual lo separa una capa más o menos complicada

de estructuras que vienen a constituir el límite o borde del organismo. Para una ameba serán la membrana celular y el glicocalix, para un mamífero el revestimiento de piel y de mucosas. Todo organismo tiene un borde, y a través de este borde el organismo intercambia con el medio materia y energía. El borde que delimita la unidad discreta circunscribe un sistema termodinámico, que recibedel medio materia y energía y se las entrega transformadas a él, o sea, delimita lo que se podría llamar un sistema dinámico físico-químico abierto y de composición muy compleja.

Lo que es fundamental tener en cuenta es que todos los organismos se caracterizan por una trayectoria de desarrollo ${ }^{7}$, de complicación, de autoorganización,la cual sigue un curso que es perfectamente previsible. Cuando se habla aquí de "trayectoria” se está aludiendo a un proceso que es continuo. Lo que significaque cualquier evento visible o detectable se inicia realmente con antelación. Porejemplo con 
la síntesis de las especies químicas que participarán en él: es evidente, tanto en las ciencias experimentales como en las experienciales que todavariable, en un proceso de desarrollo, se apoya necesariamente en una constanteque le da dirección y sentido; sin la constante la variable sería verdaderamente caótica. En otras palabras, el individuo humano se constituye por la interrelaciónintegrada de todo lo que él es y no sólo por su DNA. En la actualidad sabemos quelos genes son los elementos que definen la herencia. Sin embargo, como hemos visto recién, existen muchos elementos celulares citoplasmáticos que contienen las informaciones que dirigen, reprograman e incluso interpretan la informacióncontenida en los genes. No heredamos solamente genes sino una amplia gama deflujos moleculares que modulan y dirigen la información genética. Estos flujos son capaces de hacer que un núcleo de célula somática con cierta diferenciaciónterminal pueda direccionarse a otro estado. Más aún, nos dice Rodrigo Guerra:"Existen elementos maternos que influyen en la determinación de los fenotipos.De ahí que exista en la actualidad la opinión generalizada respecto a lo que noson sólo las informaciones del cigoto las que lo "constituyen", sino que durante un cierto tiempo se despliega un proceso en el que los elementos provenientes dela madre colaboran a la constitución de lo que eventualmente será propiamenteel programa de desarrollo. Un ejemplo a este respecto es la función de la hormona T4. Esta hormona regula la expresión de los genes del embrión que sonesencialmente para el desarrollo del sistema nervioso. Sin ella, por más que setenga un código genético completo, éste no se expresa de la manera adecuada y por ende no cumple su función plena de programa de desarrollo ${ }^{8}$. En otras palabras, el DNA del embrión no transporta toda la información programática necesaria para el desarrollo. La información está contenida en una red compleja de interacciones del conjunto celular que incluyen al genoma pero que no están limitadas por él.

Si observo un organismo de una especie determinada en un momentodado de su vida, puedo prever cuál será su estado en un instante posterior. Nosinteresa destacar que este fenómeno universal en los organismos animales de autoorganización ordenada y de curso predictible deriva directamente de que suscomponentes químicos tienen formas y propiedades que están especificadas con alta precisión, poseen entonces lo que se llama un "alto grado de información”,y desenvuelven sus reacciones de interacción química dentro de los límitesestablecidos por un borde. Todas estas propiedades son comunes a los organismos desde el primer instante de su constitución hasta la disolución del sistematermodinámico en la muerte.

Claramente este sistema empieza con la penetración del espermatozoide en el oocito. Es en ese instante en el que se generan, 
en el espacio confinado por la membrana celular, las cadenas continuas de reacciones químicas coordinadas entrelos componentes paterno y materno que caracterizan el desarrollo.

Inmediatamente,antes de ese instante, hay dos células independientes, el espermatozoide y el óvulo,que no están circunscritas por un borde común y que tienen destinos o trayectorias propios, enteramente distintos de la que se hará presente en el óvulo al ser fertilizado. Inmediatamente después tenemos un organismo en evolución.

Pero además, e insistiendo un poco sobre el desarrollo del huevo fecundado, él es claramente un organismo de la especie humana. El más simple de los estudiosde sus cromosomas así lo acredita, y más todavía lo acredita su trayectoria normal de desarrollo que a través de distintas etapas lo lleva a la adultez y la muerte.

Además, cada embrión es un sistema dinámico en el cual se combinan de manera única por lo menos dos tipos de componentes: los que constituyen sus genesy los que forman el resto de los componentes celulares, en el caso del zigoto, el citoplasma. Por razones que se entienden bien desde el ángulo físico-químico, estaspeculiaridades determinan trayectorias de desarrollo diferentes, aun en el caso de los gemelos univitelinos. Por eso, en cualquier estado de su desarrollo el embrión es un organismo humano único, distinto de todos los otros de su especie que se hallen en estado comparable de evolución.

Todo esto vale entonces desde el momento de la fecundación. Desde luego no hay ninguna razón sólida para pensar que un embrión es menos un organismo humano antes de la implantación en el útero que después de ella: los famososcatorce días del informe Warnock son un plazo absolutamente convencional ydictado por razones más bien interesadas, pero sin base conceptual que resista el análisis. Los eventos de la fecundación son muy rápidos ${ }^{9}$ : a los pocos minutos de penetrado el espermatozoide se inicia un juego recíproco entre sus componentes y los del óvulo para dar inicio a un proceso enteramente nuevo; así, el centríolo del espermatozoide gobierna los movimientos de la primera división del huevo, los productos del citoplasma ovular ayudan a descondensar la cromatina del espermio,la síntesis de ADN y la transcripción de genes aportados por el espermatozoide pueden comenzar antes de que se fusionen los pronúcleos, etc. ${ }^{10}$. Los componentesde las que fueron dos células trabajan ahora armoniosamente como partes de una sola: se ha iniciado la trayectoria (en el sentido de trayectoria en el espacio de fasesde un sistema físicoquímico), propia de un organismo.

\section{2. ¿Desde cuándo el embrión es considerado un ser humano? ${ }^{11}$}


Puesto de otro modo, ¿desde cuál momento tiene el mínimo derecho, que es el derecho a la vida?

Pensemos por un momento en este concepto tan peculiar de "derecho a la vida”. La propia existencia no es una cosa a la que uno tenga un derecho que sea de la misma especie que todos los demás. No tengo derecho a la vida en el mismo sentido en que tengo derecho a ser propietario o a expresarme libremente. El “derechoa la vida” es más bien el fundamento o condición de todos los posibles derechos y bienes. Ahora bien, ciertamente que cuando morimos de muerte natural no está violado nuestro derecho a la vida, como en cambio lo estaría si nos asesinaran. Por eso preferiríamos ahora hablar, más que de mi derecho a vivir (que puede ser una expresión vacía de contenido), del deber que tienen todos de respetar y aun de promover mi vida. Y entonces la pregunta es: ¿Desde cuándo existe ese deber respecto del embrión? Dicho de otro modo ¿desde cuándo hay que tratarlo como a una persona?

Pero las funciones de relación humanas aparecen también gradualmente,en trayectorias de desarrollo, y no está nada claro por qué -si el organismo es un sistema en desarrollo (y eso lo es siempre)se habría de preferir algún momento especial de madurez funcional y no por ejemplo el de algún fenómeno de determinación que sea irreversible. Se ha hablado entonces del instante de la aparición de las primeras neuronas, pero no queda claro qué cosa podría tener de especial este último fenómeno para darle la preferencia sobre la aparición del primer esbozo del sistema nervioso en el tubo neural, el cual aparece como una diferenciación en un organismo humano ya constituido y que se halla irreversiblemente comprometido al desarrollo de un sistema nervioso humano, y cuyo origen primero hay que buscarlo en último término mucho más atrás en el mismo comienzo de la evolución del embrión. Uno puede decir con perfecta propiedad que -desde el momento en que existe un embrión humanose hallan en alguna fase de su desarrollo las funciones de relación que le son propias. Da la impresión de que cualquier punto que se escoja para decir "aquí, en este momento, se inicia el desarrollo de las funciones de relación” es completamente arbitrario, y refleja el deseo de encontrar un punto de discontinuidad más bien que la existencia de la tal discontinuidad.

Investigar sobre el inicio biológico o genético de la vida del ser humano significa individuar el momento preciso en el cual los gametos humanos (el óvulo y elespermatozoide) son un embrión humano. Antes de ir adelante hay que hacer esta aclaración y precisión: Las células germinales humanas son "vida humana” si bien no todavía vida de un nuevo ser humano. Terminada esta aclaración volvamos a la 
pregunta ¿Cuándo los dos gametos son un ser humano? En otras palabras ¿cuándo los gametos cambian su naturaleza? O también: ¿cuándo se constituye biológica y genéticamente el ser humano? La respuesta es en el momento de la fertilización, aunqueesta respuesta es fuertemente rechazada, a la luz de los últimos descubrimientos que demuestran que la fecundación no es un acontecimiento simple, instantáneo o estático, sino un proceso dinámico y complejo que se desarrolla en el tiempo (alrededor de24 horas), desde el momento de la penetración del espermatozoide en el óvulo hasta cuando alcanza el estadio de "singamia" (o sea, el momento de la fusión completa de todos los cromosomas de las células germinales) ${ }^{12}$.

Las preguntas que se nos hacen son ¿̇la célula en "presingamia" es ya un ser humano genética y biológicamente? ¿la fertilización coincide con la penetración del espermatozoide en el óvulo o con la singamia (es decir, con el inicio y el final de ese proceso)? Es una cuestión relevante en bioética porque se trata de valorar la importancia éticojurídica de la fertilización. Dos son las tesis contrastantes: 1) La tesis de quien sostiene que el ser humano sea ya bio-genéticamente constituido desde el momento de la penetración del gameto masculino en el gameto femenino y la tesis opuesta. 2) Quien argumenta la presencia del ser humano sólo desde el momento de la singamia. Esta última tesis representa ya un intento de postergación del inicio de la vida del ser humano respecto del momento inicial de la vida humana, o sea, el momento del inicio del proceso de la fertilización ${ }^{13}$.

Los principales argumentos a favor de la tesis que sostiene el inicio del ser humano en el momento de la penetración del gameto masculino en el gameto femenino se pueden resumir en las siguientes consideraciones:

- La pérdida de la identidad separada del espermatozoide en el momento en que es incorporado en el óvulo constituyendo una única célulasingular unificada (en el momento de la penetración las membranas de las respectivas células se abren y ponen en común el material genético, iniciando una intensa actividad de mezcla y de interacción).

- La observación científica del inicio de la constitución y de la determinación de la identidad genética.

- Y finalmente, la adquisición por parte de la célula huevo fertilizada, de la "nueva capacidad" de organizar todas las fases del desarrollo sucesivode la vida humana ${ }^{14}$. 
En este sentido, la singamia no constituiría nada nuevo (por lo que se refiere a la estructuración genética). Sería sólo un momento más del proceso ya iniciado anteriormente.

Sabemos con certeza, nos dice Jerôme Lejeune, de toda la información que definirá a un individuo, que le dictará no sólo su desarrollo sino también su conducta ulterior; de ahí que sabemos que todas esas características están escritasen la primera célula. Y lo sabemos con una certeza que va más allá de toda duda razonable, porque si esta información no estuviera ya completa desde el principio, no podría tener lugar. Efectivamente, ningún tipo de información entra en un huevo después de su fecundación (...) Esa pequeña "mora” que anida en la pared del útero es ya diferente de la madre, ya tiene su propia individualidad y, lo que es difícil de aceptar, ya es capaz de dar órdenes al organismo de la madre. Este minúsculo embrión, al sexto o séptimo día, con tan sólo un milímetro y medio de tamaño, toma inmediatamente el mando de las operaciones. Es él, y sólo él, quien detiene la menstruación de la madre, produciendo una nueva sustancia que obliga al cuerpo amarillo del ovario a ponerse en marcha, fuerza a su madre a conservar su protección. Ya hace de ella lo que quiere ¡y Dios sabe que no se privará de ello en los años siguientes! ${ }^{15}$.

Las siguientes características fundamentan el hecho de que desde la fecundaciónexiste un individuo de la especie humana:

Novedad biológica, al unirse la información de las dos células germinales paradar lugar al cigoto como ser biológicamente único e irrepetible (hay que decir a este respecto que incluso los gemelos no son exactamente iguales biológicamente).

Unidad, ya que el genoma actúa como centro organizador del desarrollo del nuevo ser.

Continuidad, siendo el proceso de desarrollo un continuo desde la fecundación a la muerte.

Especificidad, ya que el genoma del cigoto pertenece a la especie homo sapiens.

Autonomía, ya que el genoma del embrión actúa de forma autónoma para dirigir el desarrollo (se entiende que la autonomía no es absoluta, hay interacción con el útero de la madre).

Capacidad de relacionarse y unirse, que varía con el desarrollo: interacción con el útero, comunicación, sexualidad. 
En este sentido se ha creado, socialmente, una gran confusión sobre el estatutodel embrión. Para distanciar conceptualmente el aborto y la selección con la eliminación de embriones respecto de la muerte de un ser humano se ha introducido la idea de que el embrión no es un individuo humano, y además se ha realizado una clasificación entre embrión y preembrión para justificar la manipulación de los primeros días del desarrollo, cuando en realidad se trata del mismo ser, con la única diferencia de su estado de desarrollo. Se cuestiona particularmente la unidad (ser uno solo) y unicidad del embrión (ser único e irrepetible).

En contra de lo expuesto hay algunas objeciones teóricas y prácticas por parte de G.R. Dunstan ${ }^{16}$, S. Buckle, K. Dawson y P. Singer ${ }^{17}$ que ponen en duda la identidad genética y biológica del ser humano en la primera fase de la formación del zigoto.

Las argumentaciones se pueden sintetizar de la siguiente manera: Del proceso del fenómeno se deduce la no identificabilidad de la existencia de un individuo (o de una identidad humana). De la posibilidad de distinguir el material genético del espermatozoide en el óvulo (aunque la cola y la membrana del espermatozoide sonabsorbidos), se infiere la negación de la unidad de la célula en presingamia ${ }^{18}$. Esto es, se trata del fenómeno del zigoto (en esa fase) con 69 cromosomas, en vez de 46 cromosomas (número característico de la especie humana) cuando son dos los espermatozoos que fecundan el óvulo y es posible un rechazo por parte del material genético.

El argumento que niega que el preembrión (los primeros 14 días del desarrollo)sea ser humano está basado en los siguientes hechos biológicos: 1) La dificultad del proceso de implantación, crítico para el desarrollo; la división celular delcigoto no siempre resulta en un embrión viable, hay un alto porcentaje que no se desarrolla por causa de fallos en el proceso de implantación. 2) El preembrión se encuentra en estado de dependencia genética, necesita de información externa para poder desarrollarse. 3) las células del preembrión poseen plena capacidad de desarrollo debido a que no están diferenciadas y son capaces de desarrollarse tanto como células fetales como extraembrionales, dependiendo de información externa, de tal manera que no todas las células se convierten en el embrión. Seplantea a su vez la cuestión de si las células totipotentes del embrión pueden ser manipuladas, ya que puede ocurrir que no tengan aún definido su destino encuanto a ser precursoras del embrioblasto que formarán las células de la masainterna o del trofoblasto (placenta); así mismo, las células de la masa interna, unas dan lugar al epiblasto y éstas al disco 
embrionario o embrión propio, y otrasoriginan el hipoblasto que producirá las estructuras extraembriónicas (saco vitelino, etc.). 4) $L a$ posibilidad de formación de gemelos antes de la implantación o de quimeras postcigóticas por unión de embriones, lo que pone en cuestión la individualidad del preembrión; de esta manera se trata de decir que no es un ser humano individual ${ }^{19}$.

Cabe señalar, respecto de estos cuestionamientos, que en el proceso de desarrollo de toda vida humana se dan con la misma necesidad una constante y una variable, esto es, un canon y un régimen de vida. La constante está definida por el hecho de que la persona es siempre la misma, no tiene muchos "yos" a lo largo de toda su vida, existe un único "yo" o persona, no obstante las inclemencias a las que el tiempo somete a la carne humana. La variable la constituye el proceso de desarrollo biológico que desde que inicia camina hacia su muerte, por lo tanto, no hay nada más que dos interrupciones en dicho proceso, la fecundación en cuanto inicio y la muerte en cuanto fin.

"El proceso no anula la individualidad ni la identidad del ente que forma partedel proceso: el proceso indica la sucesión secuencial de estados de desarrollo en el tiempo" ${ }^{20}$. No obstante, el que exista un proceso no significa la negación de la presencia de un individuo y de un sujeto con su propia identidad por ejemplo, la infancia también es un proceso y todo el ser humano hasta su muerte es un proceso,basta mirar las fotografías de la propia historia.

Entonces, reformulando la pregunta: ¿Cuál es el trato debido a un organismo que tiene tantas probabilidades de ser efectivamente una persona? Cuando hay algomuy grave que está en juego -como ser, la vida de alguien- la menor incerteza plantea un problema moral, y por eso respondemos que, ante cualquier mínimo grado de incertidumbre, se le debe al embrión el respeto que se le debe a una persona. Podemos afirmar, claro está, que el embrión es siempre un organismo humano y nos parece entonces que no hay ninguna evidencia científica que sea suficiente para negarle la condición de persona. $\mathrm{Y}$ eso tiene una importancia práctica decisivapara decidir sobre el trato que le debo dar.

Pero la observación del mundo biomédico de hoy muestra un crecientedesarrollo de acciones destructivas contra embriones y fetos: la manipulación embrionaria, el aborto, para no hablar del infanticidio, muestran a las claras que estos organismos humanos son tratados como cosas, y de ningún modo como personas. Si no hubiera otras pruebas, la atroz injusticia legal de la destrucción reciente de tres mil 
organismos humanos en Gran Bretaña serviría para ilustrar cómo el desdénpor las personas se ha hecho parte de nuestras legislaciones.

¿Qué significado tiene entonces que se le niegue al embrión el derecho a vivir? Contestamos: en el estado actual de nuestros conocimientos, no significa tanto que se pueda estar seguro de que el organismo embrionario no es una persona, cuanto que no existe un respeto adecuado a la persona humana. No significa tanto que hayadudas sobre el "status” del embrión, como que hay desdén por el hombre.

La postura tolerante frente al aborto o a la experimentación o manipulación de embriones no sería pues posible sin un trasfondo de menosprecio a la persona humana en general. Es paradójico que esa postura sea muy difícil de conciliar con las principales corrientes de las que se nutre la ética contemporánea.

Esta perplejidad emerge en un mundo práctico, racional, inspirado por elpositivismo y las ciencias naturales, para el cual la realidad es en cierto modo homogénea, y no presenta por supuesto elementos dotados de una peculiar dignidad. En otra parte hemos señalado cómo el propio conocimiento científico de la psique humana ha erosionado la experiencia del “yo", al subsumirla en el juego de las leyes naturales, y ha contribuido a desplazar el yo "fuerte" del hombre para reemplazarlo por un "yo" débil, del estilo postmoderno, el que ya no dice "yo pienso" sino "se piensa”.

La relativización y la trivialización de la vida humana, la reducción de lapersona a la categoría de objeto entre los objetos, la supresión de su carácter único e intangible, es en realidad la supresión de la manifestación por excelencia de Dios a los hombres y, por lo tanto, una verdadera negación de Dios.

No es entonces de extrañar que ese llamado vehemente a una conversiónsocial, que es la Encíclica Evangelium Vitae, se encuentre como centrada en el mandamiento de "no matarás". Éste marca ciertamente la cota mínima del amor cristiano. Pero allí donde se lo ignora y desprecia, toda vida espiritual y social termina por corromperse.

\section{4. la dignidad es constitutiva desde la concepción hasta la muerte}

Cuando hablamos de la "dignidad humana” nos parece que hay un elemento central que no puede ser sometido a comparación, que no reconoce propiamente gradación. Ningún ser humano puede estar 
sometido a nuestro arbitrio. Hay algo enmí y en cada uno de los hombres y mujeres, que nos es propio, y de lo cual nadie puede disponer. Nadie puede estar a disposición de otro como lo está el instrumento ala del operario. Esa condición del ser humano es su dignidad. Todas las cosas puedenser transables. Todas las cosas tienen precio; pero el hombre tiene dignidad.

Esa dignidad propia del hombre no existe en grados diversos. Sería absurdo decir que los hombres son más o menos explotables, más o menos usables, como se pueden usar las cosas en general. Esa dignidad "nuclear" o fundamental setiene o no se tiene. No puede haber hombre que no la tenga. Ella se adquiere con la existencia y se pierde con la muerte ${ }^{21}$.

Ser persona no es algo agregado, no es una cualidad o característica del ser humano: es la manera que tiene el ser humano de existir, de ser. La dignidad no estápues ligada a las cualidades morales, físicas o intelectuales del ser humano, sino simplemente a que éste es, al hecho de que como individuo de la especie humana tiene un lugar absolutamente especial en la creación.

Parafraseando a Faggioni, el valor de la vida humana no deriva de aquello que un sujeto hace o realiza sino simplemente de su existencia con su ser constituido en relación con Dios; la raíz del valor de la inviolabilidad de toda vida humana estáúltimamente en Dios. En consecuencia, sea joven o adulto, sano o enfermo, embrión o neonato, genio o idiota, el valor de todo ser humano es totalmente independientede la cualidad de sus prestaciones y de su vida; lo que verdaderamente cuenta es su ser en relación con Dios ${ }^{22}$.

Mientras que toda relación con el otro es reveladora de mi ser persona, la relación con Dios es constitutiva de mi ser persona. Cada uno de nosotros existe como personaporque su ser está en relación con el misterio trascendente del Ser. Si bien es verdad que cada uno de nosotros se humaniza en el momento en que viene acogido en una red de relaciones interhumanas, es también verdad que la acogida por parte del otro no constituye a la persona en su ser y en su valor. El otro no me atribuye ser y valor,sino que lo reconoce, porque mi ser y mi valor están constituidos por mi relación con la alteridad fundante, con $\operatorname{Dios}^{23}$.

A condición consciente del ser humano, nos dice F. Rielo, no acaece con el tiempo, ni con el desarrollo o madurez biológicas, ni con el cúmulo de experiencias;antes bien, la persona humana es un ser consciente, intelectivo, volitivo y libre desde el primer momento de su concepción. Otra cosa es el ejercicio experiencial de la conciencia y de 
la libertad con sus dos funciones de la inteligencia y de la voluntad en su complejidad psicosomática sometida al desarrollo y madurez en el tiempo biológico. El ser humano posee, no obstante, vivencia primordial de su consciencia y de todo lo que le constituye como persona desde el momento de su concepción, y es esta vivencia primordial, trascendente, la que está presente en toda experiencia vivencial y experiencial en el desarrollo integral durante su vida en este mundo ${ }^{24}$.

Esta afirmación se apoya en la definición de persona que da F. Rielo, desde su personal experiencia mística: definición mística del hombre ${ }^{25}$. El “yo inhabitado por Dios”, nos sigue diciendo F. Rielo, contiene en sí estos factores determinantes de unidad mucho antes de las primeras experiencias fácticas que acuden a nuestro recuerdo. La primera experiencia, en el sentido más absoluto, no es la experiencia quele pudiera derivar al embrión del mayor o menor desarrollo de su sistema nervioso o de sus sentidos, sino la experiencia de Dios, la divina presencia constitutiva, que deja a ese embrión en un estado relacional y dialogal hasta su muerte, convirtiéndoloen persona. Esta divina presencia constitutiva deja al embrión en un estado de ser, forma de ser, y razón de ser de tal manera que forman su conciencia. Le es inherenteal ser humano ser alguien con conciencia de Alguien. Ese estado de ser, conciencia de Alguien, le acompaña toda su vida, él sabe, aunque sea balbucientemente, que este mundo no es su "hábitat". Nuestro “yo", genetizado ontológicamente por la divina presencia constitutiva, es antes que nuestra efectiva capacidad del recuerdo,de nuestra memoria, de nuestra imaginación, de nuestros sentimientos, de nuestrosafectos, y, cómo no, de nuestra cultura, de nuestra educación, de nuestras formas de pensar y de actuar, de nuestros conocimientos científicos ${ }^{26}$ :

Hay que preguntarse, supuesta mi concepción genética de la metafísica, cómo adviene la persona humana. La respuesta es precisa: la persona humana, supuestoel elemento creado de su naturaleza cuerpo, alma y espíritu-, aparece constituidainmediatamente por las personas divinas y no por una noción diferente, ajena a éstas, en tal grado ontológico que la deidad mística de la persona humana participa inmediatamente de la divinidad constituida por las personas divinas; en este sentido,la persona humana no puede ser definida por otra noción diferente. La relación dela persona humana procede inmediatamente por la presencia constitutiva de las propias personas divinas. La primera manifestación, entre otras muchas de carácterfundamental, es la siguiente: la persona humana es mística trascendencia de la divina trascendencia, místico apriori del divino apriori, místico dogma del divino dogma. El llamado término dogmático tiene para mí el significado del carácter inmutable de su 
constitución en tal grado que carece de variables. El enunciado es exacto: somos mística constante de la divina constante ${ }^{27}$.

Este es el centro, la esencia de toda la dignidad del ser humano, eliminado estecarácter deitático del ser humano, éste se nos queda en una especie de homínido muy desarrollado, cuya definición, tan de moda en este momento, sobre todo en nuestro país Chile, sería la de un animal bio-psico-social que es lo mismo que decir "un ser para el cementerio". Se pretendería, entonces, explicar la libertad humana,así como todas las estructuras y operadores, genéticos ontológicamente, desde la extraordinaria complejidad de una psicología que, por definición, es un complejo de funciones variables, todas sujetas a posible y necesaria modificación, en razón de las necesidades de una visión más honda, otorgada por una conciencia moral, sin la cual la psicología es ciega. Se nos podría objetar que también la moral sin la psicología se vaciaría. Respondemos que la psicoética resultante de la imbricación de estas dos ciencias descansa en la ontología o mística, otorgada al ser humano desde el primer instante de su concepción por la divina presencia constitutiva del Acto Absoluto en el creado espíritu humano.

Las funciones sicosomáticas, sus contenidos de experiencias acumuladas, su objetivación en la historia y en la cultura, están sometidos al proceso del conocimiento, cuya experiencia se obtiene a la par que se da el desarrollo y madurez de su función biológica, de su función sicológica, de su función social, en las que intervienen las circunstancias educacionales y ambientales ${ }^{28}$.

Cristo da del ser humano la más hermosa definición que jamás se haya dado de la persona y su dignidad: Dioses sois (Jn 10,32). No divinidades, Divinidad es Él, el ser humano es una deidad, debido a la divina presencia del Sujeto Absoluto enel espíritu de todo ser humano, de ahí su linaje, su dignidad: hijo de Dios y si hijo también heredero. Todo hombre, entonces, es sagrado para todo hombre, pues todos, sin excepción, tienen la misma dignidad.

Aparece claro, entonces, que la dignidad humana, desde lo experimental, locuantificable, esto es, contemplada desde las ciencias de la naturaleza, no puede derivarse de ninguno de los órganos, tejidos, miembros, cualidades o capacidadesmayores o menores del cuerpo humano, pero tampoco la podemos derivar, en el ámbito experiencial o vivencial, de la mayor o menor inteligencia que pudierallevar a un ser humano a ejercer un rol más elevado en la pirámide del poder enla sociedad, como tampoco la podemos deducir de la riqueza o de la pobreza enque viven los seres humanos. Más allá de ser hombre o mujer, blanco o negro, rico o pobre, intelectual o ignorante, más allá 
de cualquier otra cualidad o defecto, los seres humanos tienen todos, sin excepción, la misma dignidad. Estadignidad les viene no de aquellos aspectos biológicos, psicológicos o sociales que precisamente diferencian a unos seres humanos de otros, sino de aquello queles es común y constitutivo, su filiación divina, y esto desde el instante mismode su concepción.

\section{Citas}

${ }^{1}$ A cada ser humano, desde su concepción hasta su muerte natural, se le debe reconocer la dignidad de persona. Este principio fundamental, que expresa un gran "sí" a la vida humana,debe ocupar un lugar central en la reflexión ética sobre la investigación biomédica, que reviste una importancia siempre mayor en el mundo de hoy. Congregación para la Doctrina de la Fe. Instrucción Dignitas Personae, Roma, Città del Vaticano, 15 diciembre 2008, pág. 1.

${ }^{2}$ SS. Pablo VI, Humanae Vitae. Encíclica sobre la regulación de la natalidad, 25-VII1968, 16ª Edición, Ediciones Palabra, Madrid, 1992.

${ }^{3}$ SS Juan Pablo II, Evangelium Vitae. Carta Encíclica sobre el valor y el carácter inviolablede la vida humana. ED. San Pablo. Santiago de Chile, 1995. Ver también Congregación para la Doctrina de la Fe, Instrucción Donum Vitae, del 22 de febrero de 1987, Sobre el respeto de la Vida Humana Naciente y la Dignidad de la Procreación, Ciudad del Vaticano. Roma.

${ }^{4} \mathrm{Jn}, 12,32$.

${ }^{5}$ Concilio Vaticano II, Constitución Gaudium et Spes, Parte I, Cap. 1, Dignidad de la persona humana n. ${ }^{\circ}$ 22. Octava Edición. Ed. San Pablo, Santafé de Bogotá, D.C. pág. 151.

${ }^{6}$ Vial Correa J. de D. and Dabiké M., The Embryo as an Organism in Identity and Statuteof the Human Embryo. Proceedings of the third Assembly of the Pontifical Academy for Life. Eds Juan de Dios Vial and Elio Sgreccia. Libreria Editrice Vaticana, 1998, págs. 317-331.

${ }^{7}$ Saunders Peter T. The Organism as a Dynamical System in Thinking about Biology. An Invitation to Current Theoretical Biology. Editors Wilfred Stein and Francisco J. Varela. Lecture Notes Volume III Santa Fe Institute. Sciences of Complexity Addison Wesley, 1993, pág. 4163. 
${ }^{8}$ Guerra López R. Hacia una ontología del embrión humano. En Biofilosofía, Biología deldesarrollo e Individuación humana, versión 2. Congreso Internacional en Ciudad del México, 2005. Art. publicado por la Asociación Española del Personalismo, pág. 3. Citado por A. Rodrígez Guerro, La persona en edad embrionaria, en Ars Medica n. ${ }^{\circ}$ 16, Facultad de Medicina de la Pontificia Universidad Católica de Chile. Santiago de Chile, 2008, pág. 117.

${ }^{9}$ Menezo Y., Renard J.P. The life of the egg before implantation. In Reproduction in Mammals and Man. Thibaut Ch., Levasseur MarieClaire, Hunter R.H.F eds Ellipses ed, pág. 349-363, 1993.

${ }^{10}$ Yanamigachi R. Mammalian Fertilization I, In The Physiology of Reproduction, RavenPress, 1988, pág. 135-185,

${ }^{11}$ Algunas notas de este apartado se encuentran publicadas en las siguientes obras:Rodríguez Guerro A., La persona en edad embrionaria, en Ars Medica Facultad de Medicina de la Pontificia Universiad Católica de Chile, n. ${ }^{\circ}$ 16, Santiago de Chile, 2008, pág. 107-146. También en Vial Correa J. de D. y Rodríguez Guerro A., La dignidad de la persona humana desde la fecundación hasta su muerte, en Acta Bioethica, Organización Panamericana de laSalud Fundamentación de la bioética Año XV -n. o 1-2009, pág. 55-64. Ver también Juan de Dios Vial Correa y A. Rodríguez Guerro, El embrión humano, uno de nosotros, en Ars Medica n. ${ }^{\circ}$ 17, 2008.

${ }^{12}$ Cf. Palazzani L. (1996) Il concetto di persona tra bioetica e diritto, Ed. G. Giappichelli,Torino, pág. 43: "Va dicho que en la literatura en general (y también en la literatura científica) nohay acuerdo sobre el modo de entender la singamia: para algunos, ésta coincide con la alineaciónde los cromosomas, para otros cuando inicia y termina la fusión del material genético y para otros cuando tiene inicio la división mitótica”.

${ }^{13}$ Cf., ibíd, pág. 44. Ver también Rodríguez Yunta E. El estatuto del preembrión humano,en Ars Medica, vol. 1 n. ${ }^{\circ} 1$ Pontificia Universidad Católica de Chile, pág. 98-108.

${ }^{15}$ Lejeune C. y Lejeune J. (1999) El amor a la vida. Ed. Palabra, Madrid, pág. 47-48.

${ }^{14}$ Palazzani L, óp. cit., pág. 44-45.

${ }^{16}$ Dunstan G.R. The ethical dilemmas, en Commonwealth of Australia, Senate select Committee on the Human Embryo Experimentation Bill 1985 (official Hansard Report),Commonwealth Government Printer, 
Camberra 1986, pag. 635. Las palabras de Dunstan son lassiguientes: "if conception is a process, not an event (...) then one cannot assume the existence of an individual, a human identity, at this stage”. Citado por Palazzani L, óp. cit., pág. 44-45.

${ }^{17}$ Buckle S., Dawson K., Singer P., The syngamy debate: when precisely does a human life begin?, en Singer P. (Edic.), Embryo experimentation. Ethical, legal and social issues,Cambridge University Press, Cambridge 1990, pág. 213-225.

${ }^{18}$ Ibíd, pág. 218-219.

${ }^{19}$ Cf. Bedate C.A. y Cefalo R.C., The Zygote: To Be or not to Be a Person, Journal of Medicine and Philosophy, n. ${ }^{\circ}$ 14, 1989 pág. 641645, pág. 642. Ver también Rodríguez Yunta E., El estatuto del preembrión, una perspectiva biológica, en Ars Medica n. ${ }^{\circ} 1$ Vol. 1 Pontificia Universidad Católica de Chile, Santiago de Chile, 2001, pág. 99-108.

${ }^{20}$ Palazzani L, óp. cit., pág. 45.

${ }^{21}$ Vial Correa J. de D., Rodríguez Guerro A. La dignidad de la persona humana. Desde la fecundación hasta su muerte. En Acta Bioethica, Organización Panamericana de la Salud, Fundamentación de la bioética Año XV - n. ${ }^{0}$ 1- 2009, pág. 57.

${ }^{22}$ Faggioni M. La qualità della vita e la salute alla luce dell'antropologia cristiana en Qualità della vita ed etica della salute. PAV Ed. Librería Editrice Vaticana 2006, pág. 28. Ver también De Angelis B., La divinizzazione dell'uomo in Massimo il Confessore. En DivusThomas n. ${ }^{\circ}$ 42, 3/2005-Año $108^{\circ}$; La dignità della persona umana e l'ambiente divino. Ed.Studio Domenicano. Bologna 2005, pág. 65-80.

${ }^{23}$ Cf. Faggioni M. (2006) La qualità della vita e la salute alla luce dell'antropologia cristianaen Qualità della vita ed etica della salute. PAV Ed. Librería Editrice Vaticana, pág. 28.

${ }^{24}$ Cf. Rielo F. Filosofía Sicoética. En Mis meditaciones desde el modelo genético. Ed. F.F.R. Madrid, 2001, pág. $134-135 .{ }^{25}$ Cf. Rielo F. Definición mística del hombre y el sentido del dolor humano. En Mis meditaciones desde el modelo genético, óp. cit., pág. 143-187. ${ }^{26}$ Cf. Rielo F. Concepción genética del método (inédito). 
${ }^{27}$ Rielo F. La persona no es para sí ni para el mundo. En Hacia una pedagogía prospectivaEd. F.F.R. Madrid, 1991, pág. 93-94.

${ }^{28}$ Cf. Rielo F., ibíd. 